\title{
(8)
}

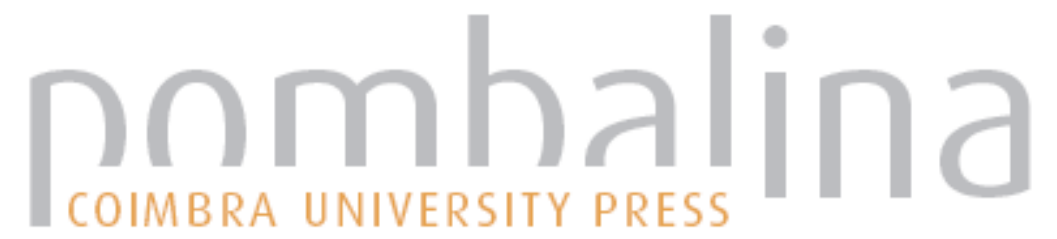

\section{Morfoestruturas do Graben do Tacutu (Centro-Nordeste de Roraima, Brasil)}
Autor(es): $\quad$ Tavares Júnior, S. S.; Nascimento, S. de O.; Neta, L. C. Beserra; Hahn, P. Y.S.

Publicado por: Imprensa da Universidade de Coimbra

URL

persistente: URI:http://hdl.handle.net/10316.2/31382

DOI: $\quad$ DOI:http://dx.doi.org/10.14195/978-989-26-0534-0_4

Accessed : $\quad$ 26-Apr-2023 11:56:37

A navegação consulta e descarregamento dos títulos inseridos nas Bibliotecas Digitais UC Digitalis, UC Pombalina e UC Impactum, pressupõem a aceitação plena e sem reservas dos Termos e Condições de Uso destas Bibliotecas Digitais, disponíveis em https://digitalis.uc.pt/pt-pt/termos.

Conforme exposto nos referidos Termos e Condições de Uso, o descarregamento de títulos de acesso restrito requer uma licença válida de autorização devendo o utilizador aceder ao(s) documento(s) a partir de um endereço de IP da instituição detentora da supramencionada licença.

Ao utilizador é apenas permitido o descarregamento para uso pessoal, pelo que o emprego do(s) título(s) descarregado(s) para outro fim, designadamente comercial, carece de autorização do respetivo autor ou editor da obra.

Na medida em que todas as obras da UC Digitalis se encontram protegidas pelo Código do Direito de Autor e Direitos Conexos e demais legislação aplicável, toda a cópia, parcial ou total, deste documento, nos casos em que é legalmente admitida, deverá conter ou fazer-se acompanhar por este aviso.

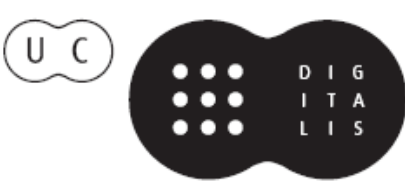





\title{
MORFOESTRUTURAS DO GRABEN DO TACUTU (CENTRO-NORDESTE DE RORAIMA, BRASIL)
}

\author{
MORPHOSTRUCTURES OF THE TAKUTU GRABEN \\ (CENTRAL NORTHEAST RORAIMA, BRAZIL)
}

\author{
S. S. Tavares Júnior ${ }^{1}$, S. de O. Nascimento ${ }^{2}$, \\ L. C. Beserra Neta ${ }^{3} \&$ P. Y. S. Hahn ${ }^{4}$
}

\begin{abstract}
Resumo - O graben do Tacutu, localizado no centro-nordeste do estado de Roraima, consiste em um segmento distensivo, correspondente a um rift intracontinental implantado no Mesozóico em uma zona de reativação do Cinturão Guiana Central, onde as principais estruturas estão orientadas preferencialmente a NE-SW. A profundidade da bacia pode chegar até sete mil metros, preenchida por uma seqüência sedimentar que vai desde o Jurássico Médio ao Quaternário, incluindo termos vulcânicos relacionados à fase pré-rift. $\mathrm{O}$ atual nível de conhecimento geológico sobre esta bacia deve-se ao interesse à exploração de óleo e gás. Neste contexto, este trabalho visou aplicação de técnicas fotointerpretativas em imagens do sensor CCD/CBERS2B, a fim de se obter o mapa morfoestrutural, entender a evolução tectônica e caracterizar os principais compartimentos geomorfológicos do graben do Tacutu. A técnica fotointerpretativa aplicada seguiu os procedimentos do método lógico sistemático, com a introdução de inovaçôes como a geração em ambiente de SIG de mapas temáticos das feiçōes lineares dos elementos de drenagem e de relevo fotointerpretadas. O mapa morfoestrutural gerado mostrou dois conjuntos de morfoestruturas, um no interior e outro nas regióes de borda do graben; ambos possuem arranjos estruturais que refletem a evolução tectono-estratigráfica, a qual este graben foi submetido. Enfim, através da metodologia empregada informaçôes mais refinadas foram obtidas, contribuindo para o conhecimento sobre a evolução morfoestrutural do graben
\end{abstract}

\footnotetext{
${ }_{1}$ Prof. do Dep. de Geologia, Igeo, Universidade Federal de Roraima, Boa Vista-RR, Brasil; stelio@dgl.ufrr.br

2 Prof. do Dep. de Geografia, Igeo, Universidade Federal de Roraima, Boa Vista-RR, Brasil; luiza@dgr.ufrr.br

3 Acadêmico de Geografia, bolsista CNPq, Igeo, Universidade Federal de Roraima, Boa Vista-RR, Brasil; silasoliv@hotmail.com

4 Acadêmico de Geologia, bolsista CNPq, Igeo, Universidade Federal de Roraima, Boa Vista-RR, Brasil; pedro_yure@hotmail.com
} 
do Tacutu e suas relaçóes com os processos tectônicos geradores, bem como deve auxiliar na elaboração de modelos prospectivos para exploração de óleo e gás.

Palavras-chave - Análise morfoestrutural; Sensoriamento remoto; Graben do Tacutu; Brasil

Abstract - The Takutu Graben, located in the central-northeast of the state of Roraima, consists of an extensional segment, corresponding to an intracontinental rift deployed in the Mesozoic in a reactivated zone of the Central Guyana Belt, where the main structures are preferentially oriented NE-SW. The depth of the basin can reach seven thousand meters, filled by a sedimentary sequence which spans from the Middle Jurassic to the Quaternary including volcanic terms related to the pre-rift. The current level of geological knowledge of this basin is due to the interest in the exploitation of oil and gas. In this context, the aim of this work is to apply photointerpretative techniques to the CCD/CBERS2B sensor images, in order to obtain morphostructural maps, understand the tectonic evolution and characterize the main geomorphologic compartments of the Takutu graben.

The photointerpretative technique applied followed the procedures of systematic logical method with the introduction of innovations like the generation, within a GIS environment, of thematic maps of the linear elements of drainage and photointerpreted relief. The generated morphostructural map has showed two sets of morphostructures, one inside of the graben and the other in its edge regions. Both of them possess structural arrangements that reflect the tectono-stratigraphic evolution of this graben. Finally, by the use of the employed methodology more refined information has been obtained, thus contributing to increase the knowledge about the morphostructural evolution of the Takutu graben and its relationship to the tectonic processes and to help in the developing of prospective models for the oil and gas exploration.

Keywords - Morphostructural analysis; Remote sensing; Takutu Graben; Brazil

\section{1 - Introdução}

A classificação do relevo em unidades morfoestruturais é comumente utilizada para expressar aquela feiçáo formada diretamente por processos tectônicos, não necessariamente relacionada à tectônica ativa. Os estudos do relevo do estado de Roraima, federação mais setentrional do Brasil, desde os trabalhos do projeto RADAMBRASIL utilizam a classificação em unidades morfoestruturais, porém usando apenas como critérios as variaçôes das formas de relevo e diferenças altimétricas. Deste modo, os estudos sobre a compartimentação geomorfológica da região do graben do Tacutu, setor NE do Estado de Roraima (Fig. 1), levam em consideração, principalmente, as implicaçôes tectono-estruturais, por meio da aplicação de técnicas de análises fotointerpretativas sobre imagens de sensores remotos, como meios auxiliares às investigaçôes geológicas, a fim de contribuir com o conhecimento geológico já adquirido para a bacia sedimentar do Tacutu e, por conseguinte, às pesquisas à exploração de óleo e gás.

A bacia sedimentar do Tacutu possui um arcabouço estrutural de caráter predominantemente distensivo, correspondente a um rifte intracontinetal implantado no Mesozóico, 
numa zona de reativação do domínio Guiana Central (CPRM, 1999). Este rifte se configura em uma geometria de um hemigraben, encaixado no Escudo das Guianas, com cerca de $300 \mathrm{~km}$ de comprimento e 30 a $50 \mathrm{~km}$ de largura, estendendo-se até a República Cooperativista da Guyana, onde passa a configurar a geometria de um graben (North Savanas Graben). As principais feições estruturais relacionadas a essa bacia consistem em hosts, anticlíneos, sinclíneos e estruturas imbricadas orientadas preferencialmente para NE-SW (EIRAS \& KINOSHITA, 1988).

A compartimentação do relevo desta região compreende unidades morfoestruturais descritas nos trabalhos de FRANCO et al. (1975), COSTA (2008) e BESERRA NETA \& TAVARES JÚNIOR (2008). Estas consistem no Planalto Residual de Roraima, borda SSE da bacia, e no seu interior o Planalto Dissecado Norte da Amazônia e o Pediplano Rio Branco - Rio Negro, estruturados respectivamente nos arenitos da Formação Serra do Tucano (VAZ et al., 2007) e nos sedimentos areno-argilosos da Formação Boa Vista (CPRM, 1999).

A partir desta classificação, estudos fotointerpretativos mono e estereoscópicos, produziram uma série de mapas temáticos em ambiente de sistemas de informaçóes geográficas (SIG), a fim de se obter o mapa morfoestrutural da área, entender sua evolução tectônica e caracterizar os principais compartimentos geomorfológicos, contribuindo assim com os estudos prospectivos para a exploração de óleo e gás no graben do Tacutu.

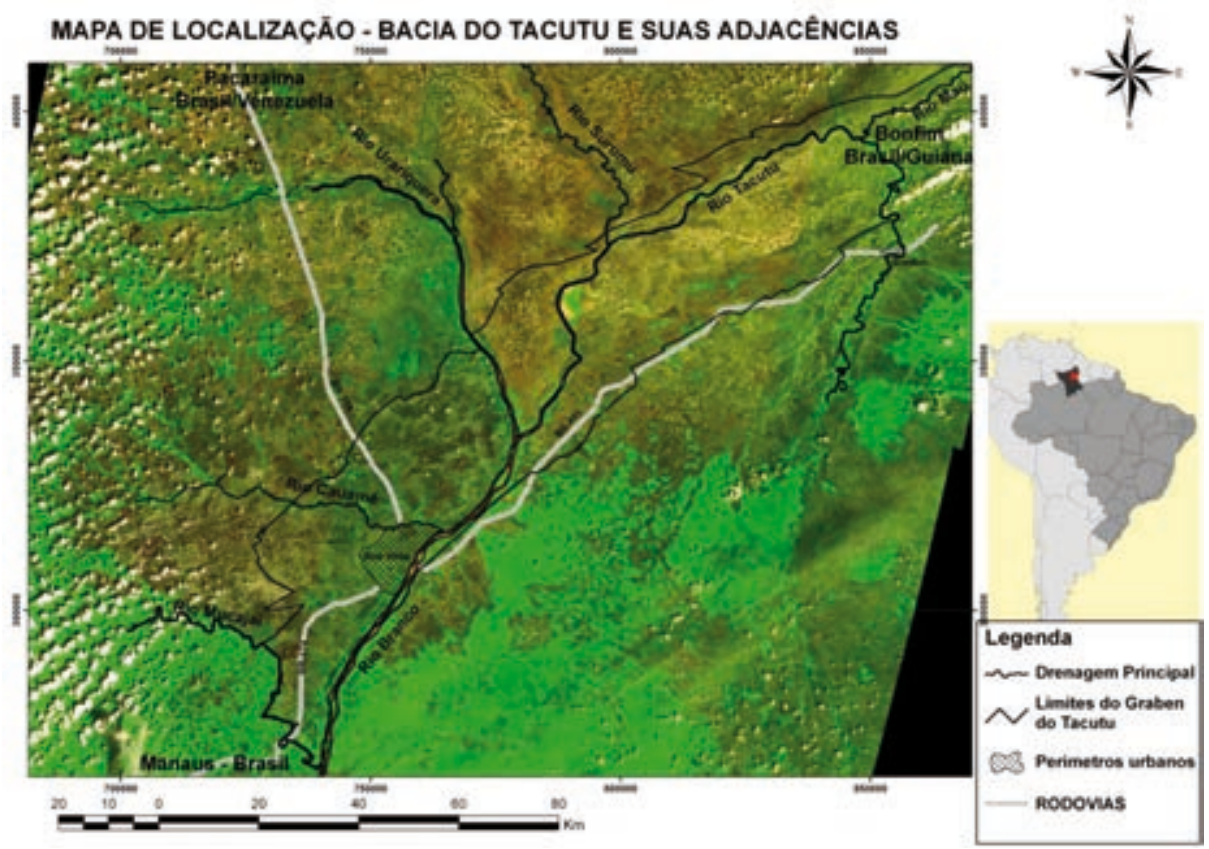

Fig. 1 - Imagem na composição colorida 3R4G2B do sensor CCD/CBERS2B, destacando os limites do graben Tacutu, as principais drenagens e a cidade de Boa Vista, capital de Roraima. 


\section{2 - Caracterização geológica}

O entendimento da evolução dos compartimentos geomorfológicos do interior e de áreas próximas ao graben do Tacutu passa por um conhecimento significativo de um referencial geológico, que engloba tanto os aspectos litoestratigráficos como tectono-estruturais. Desse modo, torna-se oportuno, mesmo que de forma sintética, apresentar as unidades litológicas aflorantes nas áreas de desenvolvimento desse estudo, cujas nomenclaturas foram definidas por CPRM (1999) e VAZ et al. (2007).

O Escudo das Guianas caracteriza-se por uma variedade de litotipos ígneos e metamórficos, resultantes da evolução geotectônica desse segmento do Cráton Amazônico. A porção estudada do Cráton Amazônico compreende o Domínio Guiana Central, englobando as províncias geotectônicas Amazônia Central, Maroni-Itacaiunas e Ventuari-Tapajós, as quais são subdivididas em unidades litoestruturais cronologicamente distintas. O Domínio Guiana Central consiste em um segmento de rochas granito-gnáissicas afetadas por deformaçóes de grande expressáo regional, mostrando forte estruturação preferencial NE-SW, bem marcada nos lineamentos estruturais, em grande parte, identificados por meio de interpretaçáo geológica em imagens de sensores remotos e magnetométricas. Os litotipos ocorrentes nesse domínio compreendem rochas do Proterozóico, a exemplo das sequências metavulcanossedimentares do Grupo Cauarane, ortognaisses da Suíte Metamórfica Rio Urubu, hiperstênios granitóides da Suíte Intrusiva Serra da Prata e granitos rapakivi da Suíte Intrusiva Mucajaí. A importância deste conhecimento recai no fato destas litologias comporem o embasamento no qual a bacia rifte do Tacutu se instalou em idades mesozóicas.

Esse segmento, representado pela bacia do Tacutu, foi responsável pela reativação das estruturas rúpteis ao longo de linhas de fraqueza crustal presentes no Domínio Guiana Central, em que essas antigas linhas possuem um controle tectônico relacionado à geometria do próprio domínio, onde é comum a ocorrência de cavalgamentos e rampas oblíquas (REIS et al., 1991). Os litotipos mesozóicos aflorantes ao longo dessa bacia rifte consistem nos derrames basálticos relacionados à fase pré-rifte, inseridos na Formação Apoteri, juntamente com as sequências areníticas da fase rifte-ativo, representadas pela Formação Serra do Tucano. Além das sequências mesozóicas, ocorrem com grande expressão regional sedimentos argilo-arenosos, inseridos na Formação Boa Vista, e areias eólicas inconsolidadas da Formação Areias Brancas, representando a fase rifte-passivo em idades cenozóicas.

\section{3 - Morfoestrutura versus Morfotectônica}

O território que compôe o estado de Roraima apresenta expressiva diversidade mineral e litológica, fruto de consideráveis eventos tectônicos transcorridos principalmente ao longo do Proterozóico, de modo que baseado em características litoestruturais REIS et al. (2003) registraram quatro principais domínios caracterizados por aspectos litológicos e estruturais distintos: Parima, Urariqüera, Guina Central e Anauá-Jatapu.

Em cada um destes domínios, diferentes formas de relevo refletem a atuação dos processos geológicos que contribuíram para suas geraçôes. Neste sentido, que se considera o estado de Roraima como típico exemplo para classificação da compartimentação geomorfológica por meio de unidade morfoestruturais de relevo, considerando, de acordo com MATOS et al. (1982), BATES \& JACKSON (1987), GONTIJO (1999) e ARAÚJO et al. (2003), 
a definição de morfoestruturas como sendo estruturas presumidas com feição topográfica, que coincide com ou é uma expressão de estrutura geológica formada diretamente por movimentos tectônicos passivos, produzidas pela interação de forças endógenas e exógenas.

Nesse sentido que se propôs a análise dos compartimentos geomorfológicos da graben do Tacutu, desde a sua região de borda até seu interior, por meio da identificação e caracterização de diferentes unidades morfoestruturais de relevo.

No caso deste graben, é claramente detectado que o controle tectônico e a sua geometria do hemi-graben foram fundamentais para a evoluçâo de morfoestruturas no seu interior e nas suas adjacências, estando intimamente relacionados aos esforços distensivos ao qual ele foi submetido durante as fases pré e sín-rifte no Mesozóico, mas também relacionadas aos esforços transpressivos e transtensivos atuantes no Cenozóico. Desse modo, é importante ressaltar o termo morfotectônica no sentido aplicado por BULL \& WALLACE (1985 apud STEWART \& HANCOCK, 1994) para estudos, que relacionam movimentos verticais e horizontais (responsáveis pela geração de estruturas neotectônicas), processos erosivos e deposicionais e a paisagem.

No entanto, no presente trabalho se desenvolveu uma análise morfoestrutural preocupada com as formas e estágios evolutivos que dão origem ao modelado do relevo, e não com a descrição e explicação de fenômenos morfológicos da atual superfície da Terra. Esta análise teve como base imagens ópticas de sensoriamento remoto e dados obtidos em campo, a fim de interpretar os elementos básicos naturais (traços de drenagem e de relevo), que refletem feições geológicas que não podem ser devidamente vistas em um modelado de relevo intensamente arrasado ou ausente.

\section{4 - Análise morfoestrutural}

O mapeamento morfoestrutural desenvolvido nesta pesquisa se iniciou a partir da análise e interpretação em imagens de sensores remotos dos elementos de drenagem e de relevo, caracterizada por zonas anômalas dentro de um padrão geral de distribuição desses elementos.

O conjunto de dados utilizados para o desenvolvimento de toda a técnica usada na análise morfoestrutural consistiu nas cartas topográficas na escala 1:100.000, elaboradas pelo Instituto Brasileiro de Geografia e Estatística (IBGE), referentes às folhas Maloca Serra da Moça, Rio Surumu, Normandia, Bonfim, Rio Tacutu, Boa Vista, Mandá-Pium e Waterloo, cenas do sensor CCD do satélite CBERS2B adquiridas entre 11/2009 e 01/2010 referentes à órbita/ponto 175/97, 175/96, 174/96, 174/97, que constituíram o mosaico para o completo recobrimento da área de estudo, dados SRTM (Shuttle Radar Topography Mission), bem como informaçóes coletadas em trabalhos de campo.

As imagens ópticas foram submetidas aos procedimentos convencionais de pré-processamento, referentes à atenuação das interferências dos constituintes atmosféricos e de redução das distorções geométricas. O primeiro, através da aplicação do método de subtração do pixel escuro (CRANE, 1971), enquanto no segundo foi aplicada a técnica de ortorretificação por meio de funçóes racionais, com a coleta regular por toda área de 48 pontos de controle no terreno, obtendo-se valores para os erros médios quadráticos entre 12 e $23 \mathrm{~m}$ para as cenas do mosaico, bem próximo do valor da resolução espacial do sensor CCD (20m).

Como a principal utilização das imagens multiespectrais foi direcionada para fotointerpretação, preferiu-se aplicar como técnica de realce a ampliação do contraste por meio 
da manipulação dos histogramas das imagens, a fim de reduzir as eventuais variaçōes de tonalidade entre as cenas mosaicadas.

A técnica fotointerpretativa aplicada nas imagens multiespectrais seguiram os procedimentos do método lógico sistemático descritos conforme VENEZIANI \& ANJOS (1982), com adaptaçóes que permitiram a elaboração e interpretação de forma integrada de mapas temáticos em ambiente de SIG, referentes à rede de drenagem, feiçóes lineares e alinhamentos de drenagem e de relevo, lineamentos estruturais, altimetria, declividade e por fim o mapa de contorno, correspondente a isomorfoestruturas.

A elaboração do mapa de contorno de isomorfoestruturas levou em consideração, principalmente, a análise integrada das propriedades dos elementos texturais de drenagem e relevo relativas à tropia, assimetria, lineaçóes estruturais com a altimetria e declividade, a fim de traçar linhas isomorfoestruturais, representantes de flexuras do terreno derivadas de processos geológicos, cujos valores são coerente e arbitrariamente definidos, conforme demonstrado por ARAÚJO et al. (2003). Deste modo, a matriz referente ao modelo numérico de terreno (MNT), e conseqüentemente o modelo digital de terreno (MDT), que no caso deste trabalho corresponde a imagem em nível de cinza das morfoestruturas, e visualizaçáo 3D puderam ser gerados, a fim de aprimorar a interpretação das morfoestruturas e, por conseguinte o entendimento da compartimentação geomorfológica.

Todos os procedimentos de processamento das imagens de Sensoriamento Remoto e de elaboração dos mapas temáticos foram realizados no Laboratório de Geotecnologias do Instituto de Geociências da Universidade Federal de Roraima (UFRR), com o uso dos aplicativos PCI Geomatics, v.10.2, Spring v. 5.1.6 e ArcGis v.9.3.

\section{5 - Mapa morfoestrutural}

A aplicação da técnica fotointerpretativa sobre as imagens multiespectrais do sensor CCD/CBER2B, integrada à interpretação dos mapas temáticos (rede de drenagem, lineamentos estruturais, altimetria, declividade e mais dados de campo) permitiram a elaboração do mapa morfoestrutural (Fig. 2 ).

Verifica-se, no referido mapa, que no interior do graben se sobressaem duas morfoestruturas em relevos topograficamente mais elevados, correspondentes às regióes conhecidas como Serra do Tucano (NE do graben) e Serra Nova Olinda (SW do graben), cujas analogias aos trabalhos de FRANCO et al. (1975) e BESERRA NETA \& TAVARES JÚNIOR (2008) correspondem, respectivamente, às unidades morfoestruturais de relevo Planaltos Dissecados Norte da Amazônia e Relevos Residuais. Estas unidades estão dispostas, principalmente, por uma sequência de morros e serras, com morfologia de cuestas e altitudes variando de 100 a 300 metros, sustentados pelas rochas areníticas da Formação Serra do Tucano vulcânicas basálticas da Formação Apoteri. Tanto na análise fotointerpretativa como nas medidas obtidas em campo, as estruturas como planos de acamamento, das falhas transcorrentes e normais e fraturas em geral mostram forte domínio da orientação NE-SW, evidenciando a relação destas morfoestruturas com uma tectônica transpressiva, resultante de reativaçóes no cenozóico.

Estas morfoestruturas estão circundadas por uma extensa área pediplanada, suavemente ondulada, constituída por sedimentos areno-argilosos da Formação Boa Vista, localmente 
interrompida por uma superfície composta por uma crosta laterítica, inserida por FRANCO et al. (1975) na unidade morfoestrutural de relevo Pediplano Rio Branco - Rio Negro.

Outras morfoestruturas mapeadas consistem em altos estruturais, tanto a norte como a sul do graben, representados por relevos residuais, cujas altitudes podem alcançar $898 \mathrm{~m}$, sustentados por um conjunto de rochas do embasamento Paleo a Mesoproterozóico, formado por ortognaisses da Suíte Metamórfica Rio Urubu, paragnaisses, quartzitos e metassedimentos do Grupo Cauarane e rochas graníticas da Suíte Intrusiva Mucajaí. Geologicamente, estas blocos rotacionados por falhas normais durante as fases pré e sín-rifte.

A partir da análise dos alinhamentos estruturais, aliada a medidas referentes às direções de planos de acamamento, falhas transcorrentes e de fraturas em geral obtidas em campo, nota-se uma forte estruturação NE-SW.

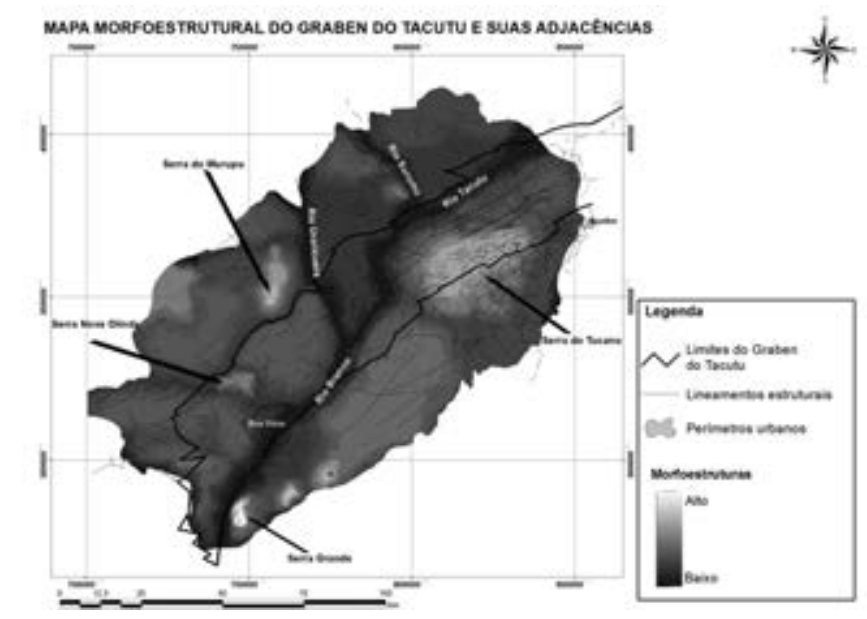

Fig. 2 - Imagem, em níveis de cinza, representando o mapa de morfoestruturas do graben do Tacutu, destacando os altos morfoestruturais do interior e das bordas do graben e notável domínio da orientação estrutural NE-SW.

\section{6 - Consideraçóes finais}

Geomorfologicamente, a área de estudo é constituída por compartimentos de relevos residuais, que situam-se na regiáo de borda do graben, tanto a norte como a sul, correspondentes a morfoestruturas que funcionam como marcadores dos limites graben.

$\mathrm{Na}$ região interior do graben, as morfoestruturas sustentadas pelos residuais vulcânicos e sequências areníticas apresentam um intenso padrão de dissecamento, e suas disposiçóes atuais podem mostrar relaçóes aos esforços transpressivos ao qual o rifte foi submetido em idades cenozóicas; porém, a forte estruturação NE-SW ainda é notada, confirmando o condicionamento estrutural, pelo menos da fase de implantação, deste graben ao domínio estrutural Guiana Central.

As extensas superfícies de aplainamento que ocorrem tanto no interior, como nas adjacências do graben, sugerem uma provável formação a partir da exumação das morfoestruturas pré-existentes na região. 
A introdução de adaptações, referentes às técnicas de geoprocessamento, à fotointerpretação pelo método lógico sistemático com intuito de gerar o mapa morfoestrutural mostrou-se eficiente, permitindo a interpretação de informaçóes mais refinadas, contribuindo de sobremaneira para o conhecimento sobre a evolução morfoestrutural do hemi-graben Tacutu e suas relaçóes com os processos tectônicos geradores, bem como deve auxiliar na elaboração de modelos prospectivos a exploração de bens minerais.

\section{Referências Bibliográficas}

ARAÚJO, C. C., YAMAMOTO, J. K. \& MADRUCCI, V. (2003) - Análise Morfoestrutural em Área de ocorrência de Arenito Asfáltico, Bacia do Paraná, São Paulo. Revista do Instituto Geológico, 24, p. 25-41.

BATES, R.L. \& JACKSON, J.A. (1987) - Glossary of Geology. American Geological Institute, Alexandria, Virginia, $788 \mathrm{p}$.

BESERRA NETA, L. C. \& TAVARES JÚNIOR, S. S (2008) - Geomorfologia do Estado de Roraima por Imagens de Sensores Remotos. In: Silva, P. R. F. \& Oliveira, R. S. (org.). Roraima 20 Anos: As Geografias de um Novo Estado. Ed. UFRR. Boa Vista, p. 168-192.CPRM - Companhia de Pesquisa de Recursos Minerais (1999) - Programa Levantamentos Geológicos Básicos do Brasil. Projeto Roraima Central, Folhas NA.20-X-B e NA.20-X-D (inteiras), NA.20-X-A, NA.20-X-C, NA.21-V-A e NA.21-VC (parciais). Escala 1:500.000. Estado do Amazonas. Brasília: CPRM, CD-ROM

COSTA, J. A. V. (2008) - Compartimentação do relevo do estado de Roraima. In: Oliveira, R. S. (org.). Roraima em foco: pesquisas e apontamentos recentes. Ed. UFRR. Boa Vista, p. 77-107

CPRM - Companhia de Pesquisa de Recursos Minerais (1999) - Programa Levantamentos Geológicos Básicos do Brasil. Projeto Roraima Central, Folhas NA.20-X-B e NA.20-X-D (inteiras), NA.20-X-A, NA.20-X-C, NA.21-V-A e NA.21-VC (parciais). Escala 1:500.000. Estado do Amazonas. Brasília:CPRM, CD-ROM

CRANE, R. B. (1971) - Preprocessing techniques to reduce atmospheric and sensor variability in multispectral scanner data. In: International Symposium on Remote Sensing of Environment, 7., Michigan, 1971, Proceedings. Michigan: Environment Research Institute, p. 1345-1355.

EIRAS, J. F. \& KINOSHITA, E. M. (1988) - Evidências de movimentos transcorrentes na bacia do Tacutu. In: Anais do XXV Congresso Brasileiro de Geologia, Belém, Pará, 5.

FRANCO, E. M. S., DEL'ARCO, J. O. \& RIVETTI, M. (1975) - Geomorfologia da folha NA.20 Boa Vista e parte das folhas NA.21 Tumucumaque, NB.20 Roraima e NB.21. In: Brasil. Projeto RADAMBRASIL. Rio de Janeiro: DNPM, 8, p.139-180.

GONTIJO, A. H. F. (1999) - Morfotectônica do médio vale do rio Paraíba do Sul: região da Serrada Bocaina, estados de São Paulo e Rio de Janeiro. Tese de Doutoramento, 259 p.

MATTOS, J. T., BALIEIRO, M. G., SOARES, P. C., BARCELLOS, P., MENESES, P. R. \& CSORDAS, S. M. (1982) - Análise morfoestrutural com uso de imagens MSS/Landsat e Radar para pesquisa de hidrocarbonetos no Estado de São Paulo. Relatório INPE-2445-RTR/015. São José dos Campos, 170 p.

REIS, N. J., SANTOS, J. O. S., RIKER, S. R. L., PESSOA, M. R., PINHEIRO, S. S. (1991) - A cobertura sedimentar Roraima na serra das Surucucus - enfoque a seus ambientes deposicionais. In: Simpósio de Geologia da Amazônia, 3, Belém, 1991. Anais. Belém: SBG/NO, 1991, p. 361-370.

REIS, N. J., FRAGA, L. M., FARIA, M. S. G. \& ALMEIDA, M. E. (2003) - Geologia do estado de Roraima, Brasil. Geologie de la France, 2-4, p. 121-134.

STEWART, I. S. \& HANCOCK, P. L. (1994) - Neotectonics. In: Hancock, P. L. (eds.). Continental Deformation. Pergamon Press, New York, p. 370-409.

VAZ, P. T., WANDERLEY FILHO, J. R. \& BUENO, G. V. (2007) - Bacia do Tacutu. B. Geoci. Petrobras, Rio de Janeiro, 15, p. 289-297.

VENEZIANI, P. \& ANJOS, C. E. (1982) - Metodologia de interpretaçăo de dados de Sensoriamento Remoto e aplicaçōes em Geologia. São José dos Campos, INPE, (INPE-2227-MD/014), 54p. 